\title{
Knowledge on obstetric danger signs among antenatal mothers attending a tertiary level hospital, Nepal
}

\author{
Binu Thapa, Krishnaa Manandhar
}

Department of Nursing, Kathmandu University School of Medical Sciences, Dhulikhel, Kavre, Nepal

Correspondence

Ms Binu Thapa

Department of Nursing

Kathmandu University School

of Medical Sciences

Dhulikhel, Kavre, Nepal

\section{Email:}

arshubinu@gmail.com

DOI: http://dx.doi.org/10.3126/ jemsn.v13i4.18093

Orcid ID: orcid.org/0000-0002 $-3883-6490$

Article received: Aug $24^{\text {th }} 2017$ Article accepted: Dec $18^{\text {th }} 2017$

\begin{abstract}
Background \& Objectives: All pregnant women are at risk and can face problems at any time during or following pregnancy and childbirth which can cause death of mothers. Knowledge of key danger signs is essential for motivating women to seek skilled attendance at birth and also to seek referral in case of complications which definitely improves health of the mother and newborns. This study aimed to assess pregnant womens' knowledge about obstetric danger signs and its associated factors. Materials \& Methods: Quantitative approach with a facility based cross -sectional study was conducted among pregnant mothers attending Anti Natal Clinic of Dhulikhel hospital, Nepal. Data was collected from 1st June to 25 th June 2017. Sampling technique was non probability, purposive sampling technique. A standardized tool was adopted. Face to face interview technique was used. Data had been processed by SPSS 20 version then analyzed using descriptive as well as inferential statistic. Results: Two third of the respondents $(66.0 \%)$ had adequate knowledge on obstetric danger signs, while $21.0 \%$ of respondents had inadequate knowledge and few respondents $(13.0 \%)$ had moderate knowledge on that. Age, educational status and gravida were not significantly associated with knowledge on obstetric danger signs but occupation and trimester of pregnancy were found to be associated with the same. Conclusion: A significant proportion of pregnant women do not have adequate knowledge on obstetric danger signs. Therefore, the quality of health information about obstetric danger signs during ANC follow up is to be improved.
\end{abstract}

Key words: Antenatal mother; Knowledge; Obstetric danger signs

Citation: Thapa B, Manandhar K. Knowledge on obstetric danger signs among antenatal mothers attending a tertiary level hospital, Nepal. JCMS Nepal. 2017;13(4):383-7.

\section{INTRODUCTION}

Preventable mortality and morbidity remains a difficult challenge in many developing countries like Nepal. Every pregnant woman faces the risk of sudden, unpredictable complications that could contribute for maternal and neonatal death. ${ }^{1}$ Each year approximately 287,000 women die from complications related to pregnancy and childbirth; $99 \%$ of these deaths occurring in developing countries. Maternal mortality ratio in developing regions is fifteen times higher than in developed regions. $^{2}$

Obstetric danger signs are problems that mothers experience during pregnancy, labour and the postpartum period such as bleeding from the vagina, swelling of the face or hands, severe headache, sudden escape of fluid from the vagina and less fetal movement. ${ }^{3,4}$ This may lead to obstetrical complication that needs an early management. The major proportion of maternal deaths is caused by obstetric hemorrhage (28\%) mostly during or just after delivery, followed by complications of unsafe abortion (19\%); pregnancyinduced hypertension (17\%); infection (11\%); and obstructed labor (11\%). ${ }^{5}$ Main attributing factors for high maternal mortality in Nepal are the 'three delays'. Lack of awareness about obstetric danger signs is the important factor for delay in seeking help. ${ }^{6}$

A study conducted in Arba Minch Town, Ethiopia which showed that $24.1 \%$ respondents were knowledgeable while $75.9 \%$ were not 
knowledgeable about obstetric danger signs. Community based descriptive study done in Rautahat district of Nepal showed that only 11\% respondents had knowledge about obstetrical danger signs. ${ }^{8}$

In Nepal, maternal mortality rate is significantly high due to life threatening obstetric complications which could be prevented if women are made aware about and able to identify obstetric danger signs. ${ }^{9}$ But available studies indicate that mothers do not have enough knowledge about it. So, researcher is interested to assess the knowledge regarding obstetric danger signs and its associated factors among pregnant mothers at Dhulikhel hospital, Nepal.

\section{MATERIALS AND METHODS}

Quantitative approach with a facility based crosssectional study was conducted among pregnant mothers attending ANC OPD of Dhulikhel hospital, Nepal. Data was collected from $1^{\text {st }}$ June to $25^{\text {th }}$ June 2017. The sample size was determined by using the following formula: $\mathrm{n}=\left(\mathrm{Z}^{2} \times \mathrm{pq}\right) \div \mathrm{L} 2$. Estimated proportion (p) was taken $58 \%$ based on literature review. ${ }^{10}$ Hence the calculated sample size was 300 . Sampling technique was non probability, purposive sampling technique.

Structured questionnaire was used for data collection on the basis of research objectives. The tools consisted of socio-demographic information and knowledge regarding obstetric danger signs. The socio demographic characteristics were developed by the researcher to collect the demographic data of the sample. It consisted of nine items. A standardized tool, which was developed by the Maternal Neonatal Program of JHPIEGO, an affiliated of John Hopkins University was adopted to assess knowledge regarding obstetric danger signs and some modification was done as per need. Structured knowledge questionnaire consisted of 10 items which were multiple choice questions as well as multiple responses. Score one was given for each correct answer and zero for wrong answer and no response. For multiple response questions, score one was given for each options and zero score was given for don't know and no response. All questionnaires were translated into Nepali. Data collection tool was pre-tested in $10 \%$ of the total sample. Those participants included in pretest were excluded in the main study and necessary corrections were done. Knowledge of respondent was categorized as inadequate, moderate and adequate knowledge. Inadequate knowledge: It refers to score gained by the respondent that is less than $50 \%$. Moderate knowledge: It refers to score gained by the respondent that is 50 to $75 \%$. Adequate knowledge: It refers to score gained by the respondent that is more than $75 \%$.

Face to face interview technique was used for data collection. The time duration for interview was 20 to 25 minutes for each respondent. An ethical clearance was obtained from IRC-KUSMS prior to the study. The purpose of the study was explained to the participants. Informed written consent was obtained from each respondent prior to interview. Privacy and confidentiality of the respondents was maintained. Information of the respondents was used only for the research. All the reproductive age group pregnant women who were attending in ANC OPD for Antenatal checkup were included in this study. Those pregnant mothers who were severely ill during data collection, unable to hear, unable to respond to the questions and who belonged to health related field (FCHV, ANM, CMA, HA, Nurse, Doctors) were excluded from this study. Styx $(*)$ sign was written on the top of the OPD card to avoid the repetition of the sample.

SPSS version 20.0 was used for data analysis. Data was analyzed by using descriptive statistical method like: frequency, percentage, mean and inferential statistics like chi square test to find out the association between socio-demographic variables with knowledge regarding obstetric danger signs.

\section{RESULTS}

Out of 300 respondents, most of participants (92.3\%) belonged to age group 20 to 40 years. Majority of participants $(81.7 \%)$ were Hindu. Ethnicity wise, Newar represented the major proportion $(26.0 \%)$ while the least was represented by Gurung (2.7\%). Majority (35.7\%) of respondents had higher secondary educational qualification. Many of respondents' (60.7\%) occupation was homemaker. More than half of respondents $(53.0 \%)$ were multigravida. More than two fifth of respondents $(44.3 \%)$ belonged to third trimester of pregnancy (Table 1).

\section{Knowledge on danger signs during pregnancy}

Among 300 respondents, most of the respondents $(89.3 \%)$ knew that vaginal bleeding is a danger sign during pregnancy, whereas blurred vision was another danger sign identified by $64.0 \%$ of 
Table 1. Socio-Demographic information of the respondents $(\mathrm{n}=\mathbf{3 0 0})$

\begin{tabular}{|c|c|c|c|}
\hline Variables & Category & $\mathrm{n}$ & $\%$ \\
\hline \multirow{3}{*}{$\begin{array}{l}\text { Age in } \\
\text { years }\end{array}$} & $16-25$ years & 188 & 62.6 \\
\hline & $26-35$ years & 110 & 36.7 \\
\hline & $36-45$ years & 2 & 0.7 \\
\hline \multirow{6}{*}{ Religion } & Hindu & 245 & 81.7 \\
\hline & Buddhist & 45 & 15.0 \\
\hline & Christian & 8 & 2.7 \\
\hline & Muslim & 2 & 0.7 \\
\hline & Brahmin & 61 & 20.3 \\
\hline & Chhetri & 76 & 25.3 \\
\hline \multirow{3}{*}{ Ethnicity } & Newar & 78 & 26.0 \\
\hline & Gurung & 8 & 2.7 \\
\hline & Tamang & 49 & 16.3 \\
\hline \multirow{10}{*}{$\begin{array}{l}\text { Education- } \\
\text { al status }\end{array}$} & Magar & 28 & 9.3 \\
\hline & $\begin{array}{l}\text { Can read and } \\
\text { write }\end{array}$ & 21 & 7.0 \\
\hline & Primary level & 17 & 5.7 \\
\hline & $\begin{array}{l}\text { Lower secondary } \\
\text { level }\end{array}$ & 29 & 9.7 \\
\hline & Secondary level & 80 & 26.7 \\
\hline & Higher secondary & 107 & 35.7 \\
\hline & Master \& above & 46 & 15.3 \\
\hline & Home maker & 182 & 60.7 \\
\hline & Agriculture & 42 & 14.0 \\
\hline & Business & 35 & 11.6 \\
\hline \multirow{2}{*}{ Occupation } & Service & 38 & 12.7 \\
\hline & Others & 3 & 1.0 \\
\hline \multirow{3}{*}{ Gravida } & Primigravida & 141 & 47.0 \\
\hline & Multigravida & 159 & 53.0 \\
\hline & 1 st trimester & 48 & 16.0 \\
\hline \multirow{2}{*}{$\begin{array}{c}\text { Trimester } \\
\text { of pregnan- } \\
\text { cy }\end{array}$} & 2nd trimester & 119 & 39.7 \\
\hline & 3rd trimester & 133 & 44.3 \\
\hline
\end{tabular}

respondents. Most of the respondents (89.7\%) had knowledge that pregnant woman can die from any of these problems and almost all of respondents (98.3\%) knew that they should go to the health center immediately if any danger signs occur during pregnancy (Table 2).

\section{Knowledge on Danger Signs during labor and childbirth}

Majority of the respondents $(79.0 \%)$ knew that prolonged labour is a danger sign during childbirth and $58.7 \%$ identified that fits was another danger sign. Most of the respondents (93.0\%) had knowledge that pregnant woman can die from any of these problems and almost all of respondents (97.7\%) knew that they should go to the health center immediately if any danger signs occur during delivery (Table 3 ).

\section{Knowledge on danger signs during post partum period}

Most of the respondents (88.3\%) knew that severe vaginal bleeding is a danger sign during post partum period. Three fifth of respondents $(60.3 \%)$ identified that blurred vision is also danger sign

Table 2: Knowledge on danger signs during pregnancy $(\mathbf{n}=300)$

\begin{tabular}{|lcc|}
\hline \multicolumn{1}{|c}{ Danger signs * } & $\begin{array}{c}\text { Number of } \\
\text { respondents } \\
\text { who had } \\
\text { knowledge }\end{array}$ & $\%$ \\
\hline Vaginal bleeding & 268 & 89.3 \\
\hline $\begin{array}{l}\text { Severe lower abdominal } \\
\text { pain }\end{array}$ & 248 & 82.7 \\
\hline Loss of fetal movement & 238 & 79.3 \\
\hline Foul vaginal discharge & 235 & 78.3 \\
\hline Severe vomiting & 229 & 76.3 \\
\hline Swollen hands, legs and face & 223 & 74.3 \\
\hline Fits & 211 & 70.3 \\
\hline Water breaks without labor & 206 & 68.7 \\
\hline Severe headache & 205 & 68.3 \\
\hline Blurred vision & 192 & 64.0 \\
\hline
\end{tabular}

(*) indicates multiple response

Table 3: Knowledge on danger signs during labor and childbirth $(n=300)$

\begin{tabular}{lcc}
\multicolumn{1}{c}{ Danger signs * } & $\begin{array}{c}\text { Number of re- } \\
\text { spondents who } \\
\text { had knowledge }\end{array}$ & $\%$ \\
\hline $\begin{array}{l}\text { Prolonged labor } \\
\text { Severe Vaginal bleeding } \\
\text { during delivery }\end{array}$ & 237 & 79.0 \\
Cord prolapsed & 214 & 73.0 \\
\hline Retained placenta & 211 & 71.3 \\
Blurred vision & 211 & 70.3 \\
Footling & 208 & 69.3 \\
$\begin{array}{l}\text { Water breaks without la- } \\
\text { bor }\end{array}$ & 206 & 68.7 \\
Hand prolapsed & 204 & 68.0 \\
Severe headache & 192 & 64.0 \\
Fits & 176 & 58.7
\end{tabular}

(*) indicates multiple response 
after delivery. Most of the respondents (88.7\%) had knowledge that postnatal mother can die from any of these problems and almost all of respondents (97.7\%) knew that they should go to the health center immediately if any danger signs occur during post partum period (Table 4).

\section{Overall Knowledge}

Out of 300 respondents, two third of the respondents $(66.0 \%)$ had adequate knowledge on obstetric danger signs. One fifth of respondents $(21.0 \%)$ had inadequate knowledge and few

Table 4: Knowledge on danger signs during post partum period $(n=300)$

\begin{tabular}{|lll|}
\multicolumn{1}{c}{ Danger signs * } & $\begin{array}{l}\text { Number of re- } \\
\text { spondents who } \\
\text { had knowledge }\end{array}$ & $\%$ \\
\hline Severe Vaginal bleeding & 265 & 88.3 \\
\hline Lower abdominal pain & 227 & 75.7 \\
\hline High fever & 218 & 72.7 \\
\hline Foul vaginal discharge & 214 & 71.3 \\
\hline Fits & 204 & 68.0 \\
\hline Severe headache & 193 & 64.3 \\
\hline Blurred vision & 181 & 60.3 \\
\hline
\end{tabular}

(*) indicates multiple response

Table 5. Overall Knowledge Level Regarding Obstetric Danger Signs $(\mathbf{n}=\mathbf{3 0 0})$

\begin{tabular}{|lll|}
\hline Level of knowledge & Number & $\%$ \\
\hline $\begin{array}{l}\text { Inadequate } \\
\text { knowledge }\end{array}$ & 63 & 21.0 \\
\hline Moderate knowledge & 39 & 13.0 \\
\hline Adequate knowledge & 198 & 66.0 \\
\hline
\end{tabular}

respondents $(13.0 \%)$ had moderate knowledge on that (Table 5).

\section{Association between Overall Knowledge Levels and selected socio demographic variables}

Age, educational status and gravida were not significantly associated with overall knowledge on obstetric danger signs but occupation and trimester rof pregnancy were found to be associated with the same at $<0.05$ level of confidence (Table 6).

\section{DISCUSSION}

In the present study we found that most of the respondents $(89.3 \%)$ identified that vaginal bleeding is a danger sign during pregnancy, which is higher than the finding of similar study done in Uganda (49\%). ${ }^{10}$ This difference might be due to setting of the study that is ANC OPD. And this finding was similar to study done in India $(90.5 \%) .{ }^{11}$

Present study also found that majority of the respondents $(79.0 \%)$ knew that prolonged labour is a danger sign during childbirth. This finding is higher than study done in Ethiopia (28.4\%). ${ }^{7}$ This difference might again be due to setting of the study.

In regard with knowledge on danger signs during postpartum period, most of the respondents $(88.3 \%)$ knew that severe vaginal bleeding is a danger sign. This finding was consistent with the findings of the study conducted in Ethiopia (89.2\%). ${ }^{7}$ This finding is higher than study done in Uganda $(57.0 \%) .10$ This difference might be due to facility based survey.

This study showed that, $66.0 \%$ had adequate

Table 6. Association between variables under study and level of Knowledge

$\mathrm{n}=300$

\begin{tabular}{|c|c|c|c|c|c|}
\hline \multirow[b]{2}{*}{ Variables } & \multirow[b]{2}{*}{ Category } & \multicolumn{3}{|c|}{ Level of Knowledge } & \multirow[b]{2}{*}{$\mathrm{p}$ - value } \\
\hline & & $\begin{array}{c}\text { Inadequate } \\
\text { knowledge N/\% }\end{array}$ & $\begin{array}{c}\text { Moderate } \\
\text { knowledge } \\
\text { N/\% }\end{array}$ & $\begin{array}{c}\text { Adequate } \\
\text { knowledge } \\
\text { N/\% }\end{array}$ & \\
\hline \multirow[b]{2}{*}{ Age in years } & Less than 25 & $39(22.8)$ & $22(12.9)$ & $110(64.3)$ & \multirow[b]{2}{*}{0.673} \\
\hline & 25 and above & $24(18.6)$ & $17(13.2)$ & $88(68.2)$ & \\
\hline \multirow[b]{2}{*}{ Education } & School level & $28(19)$ & $18(12.2)$ & $101(68.7)$ & \multirow[b]{2}{*}{0.616} \\
\hline & Above school level & $35(22.9)$ & $21(13.7)$ & $97(63.7)$ & \\
\hline \multirow[b]{2}{*}{ Occupation } & Unemployed & $44(19.6)$ & $24(10.7)$ & $156(69.6)$ & \multirow[b]{2}{*}{0.047} \\
\hline & Employed & $19(25.0)$ & $15(19.7)$ & $42(55.3)$ & \\
\hline \multirow[b]{2}{*}{ Gravida } & Primigravida & $37(26.2)$ & $19(13.5)$ & $85(60.3)$ & \multirow[b]{2}{*}{0.089} \\
\hline & Multigravida & $26(16.4)$ & $20(12.6)$ & $113(71.1)$ & \\
\hline \multirow{3}{*}{$\begin{array}{l}\text { Trimester of } \\
\text { pregnancy }\end{array}$} & 1 st trimester & $16(33.3)$ & $6(12.5)$ & $26(54.2)$ & \multirow{3}{*}{0.032} \\
\hline & 2nd trimester & $28(23.5)$ & $11(9.2)$ & $80(67.2)$ & \\
\hline & 3rd trimester & $19(14.3)$ & $22(16.5)$ & $92(69.2)$ & \\
\hline
\end{tabular}


knowledge on obstetric danger signs, while $21.0 \%$ had inadequate knowledge and few respondents $(13.0 \%)$ had moderate knowledge. Finding of adequate knowledge is higher than study done in Nepal (3.6\%) and finding of inadequate and moderate knowledge are lower $(44.4 \%$ and $52.0 \%) .{ }^{12}$ These differences in knowledge level could be due to a difference in socio- demographic characteristics.

Age, educational status and gravida were not significantly associated with overall knowledge on obstetric danger signs but occupation and trimester of pregnancy were found to be associated with the same. The finding of this study is similar with a study conducted in Ethiopia. ${ }^{?}$

\section{CONCLUSION}

This study showed that significant proportion of the pregnant women had inadequate and moderate knowledge on obstetric danger signs. This indicates the large proportions of pregnant women who do not have adequate knowledge are likely to delay in deciding to seek care, which significantly contribute to the maternal and neonatal morbidity and mortality. Therefore, urgent attempts to be made for designing appropriate strategies including provision of health education or provide information and communication to pregnant mothers to increase their knowledge. Thus, enable early recognition of serious health problems during pregnancy, labor and postpartum period which can directly help to save the life of mothers and newborns.

\section{ACKNOWLEDGEMENTS:}

We would like to express our sincere gratefulness to all the participants of the study for their cooperation. We would also like to thank Satya Shrestha from nursing department for their expert advices on statistical analysis.

\section{REFERENCES}

1. United Nations. The Millennium Development Goals Report. [Internet]. 2015 Jul 1 [cited 2017 Jul 2]:38-40. Available from: http://www.un.org/millenniumgoals/ reports.shtml

2. Shrestha B. Maternal mortality in hilly districts of Nepal. JIOM. 2009;31(2):7-8.

3. MNH Program, JHPIEGO, an affiliate of Johns Hopkins University. Monitoring birth preparedness and complication readiness: tools and Indicators for maternal and newborn health. [Internet]. 2004 [cited 2017 Jul 3]:125. Available from: http://pdf.usaid.gov/pdf_docs/ PNADA619.pdf

4. MNH Program. Birth Preparedness and Complication Readiness: A Matrix of Shared Responsibilities. [Internet]. 2001[cited 2017 Jul 3]:1-7. Available from: http:// www.commonhealth.in/neonatal-pdf/145.pdf

5. World Health Organization: Ten facts on Maternal Health. GC4W Women's Health. [Internet]. 2017 Jul 24 [cited 2017 Aug 3]:[about 3 p.]. Available from: https:// gc4women.org/world-health-organization-ten-factsmaternal-health/

6. Shrestha R. Maternal Mortality in Nepal: Addressing the Issue. Inquiries Journal. 2012;4(10):1-4.

7. Workineh Y, Hailu D, Gultie T, Degefu N, Shimeles M, Mahino M. Knowledge of Obstetric Danger Signs and its Associated Factors in Arba Minch town, Ethiopia. ajhr. 2014;2(5):255-259. j.ajhr.20140205.16. https://doi.org/10.11648/

8. Jha NK. Factors Associated with First delay to Seek Emergency Obstetric care Services among the Mother of Matsari VDC of Rautahat District. Journal of Health and Allied Science. 2012;2(1):54-56. 21.

9. Ministry of Health \& Population, USAID, New ERA. Nepal demographic \& health survey. [Internet]. 2006 [cited 2017 Jul 8]:132-134. Available from: https:// dhsprogram.com/pubs/pdf/FR191/FR191.pdf

10. Sandberg J, Odberg Pettersson K, Asp G, Kabakyenga J, Agardh A. Inadequate Knowledge of Neonatal Danger Signs among Recently Delivered Women in Southwestern Rural Uganda. PLoS ONE. 2014;9(5): e97253. https:// doi.org/10.1371/journal.pone.0097253

11. Bililign N, Mulatu T. Knowledge of obstetric danger signs and associated factors among reproductive age women in Raya Kobo district of Ethiopia: A community based crosssectional study. BMC Pregnancy and Childbirth. 2017;17:70. doi:10.1186/s12884-017-1253-4. https:// doi.org/10.1186/s12884-017-1253-4.

12. Acharya T, Poudel A. Knowledge Regarding Obstetric Danger Signs among Antenatal Mothers Attending a Tertiary Level Hospital, Nepal. IJNRP. 2016;3(2):31-40. 